THE INTERNATIONAL

REVIEW OF RESEARCH IN

OPEN AND DISTANCE LEARNING

\title{
Developing and Deploying OERs in sub-Saharan Africa: Building on the Present
}
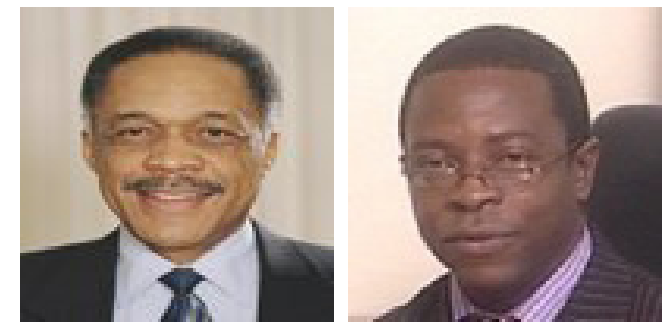

Clayton R. Wright

Canada

Sunday A. Reju

Polytechnic of Namibia, Namibia

\section{Abstract}

Open educational resources (OERs) have the potential to reduce costs, improve quality, and increase access to educational opportunities. OER development and deployment is one path that could contribute to achieving education for all. This article builds on existing information and communication technology (ICT) implementation plans in Africa and on the experiences of organizations and initiatives such as the African Virtual University (AVU), OER Africa, the South African Institute of Distance Education (SAIDE), and the Teacher Education in Sub-Saharan Africa (TESSA) Project, to present one view of the benefits, challenges, and steps that could be taken to realize the potential of OERs in sub-Saharan Africa. Thus, the article focuses on the factors necessary for creating and sustaining a vision for OER development and deployment; developing and distributing resources with an open license; improving technology infrastructure and reducing the cost of Internet access; establishing communities of educational collaborators; sustaining involvement in the OER initiative; producing resources in interoperable and open formats; establishing and maintaining the quality of OERs; providing local context to address national and regional needs and conditions; informing the public about OERs; and taking the initiative to build on the knowledge, skills, and experiences of others. In order to assist educators and decision makers, links to a variety of resources are provided.

Keywords: Open educational resources; OER; ICT; ODL, distance education; online learning; self-learning; copyright; education; education for all; educational collaborators; open source; Africa; sub-Saharan Africa 


\section{The Potential of OERs in sub-Saharan Africa}

This article provides a rationale for the use of open educational resources (OERs) as well as the potential and challenges associated with their development and deployment in subSaharan Africa. Examples of how OERs are developed and used are presented in conjunction with links to resources that may assist educators and government leaders in countries with developing or weak economies.

What do the people below have in common?

- Grace Mukami is an upper-primary school teacher in Kenya. She feels she works best with older children, though she would like to teach at the secondary level. In order to do so, Grace must update her teaching credentials and learn more about secondary-school subjects and pedagogy, especially about competency-based learning.

- Bethel Msiska was born and raised at the edge of Lilongwe, Malawi. She excels in most subjects, but her mathematical skills are weak. If Bethel could improve her grades in mathematics, she might be able to obtain a college scholarship. If she succeeded, she would be the first person in her extended family to go to college. Unfortunately, her parents only completed primary school and are unable to help her with mathematics. In addition, they cannot afford a tutor.

- Sunday Adebanjo is a Nigerian farmer who grows vegetables to feed his family. He also raises poultry and goats, which he sells in the market. In order to support his growing family, Sunday is considering raising and selling pigs. Should he instead find ways to raise his poultry more efficiently? Information about raising pigs and poultry efficiently would be useful, but a decision-making tool that would help him decide whether to diversify would be extremely valuable.

- Rebecca Kutuso is a nurse in a small town in Botswana on the main trucking route from South Africa to Zimbabwe and Zambia. She deals mostly with cuts and bruises and reminds people to use their mosquito nets. Malaria isn't as prevalent here as it is in The Gambia, where she worked previously. Instead, Rebecca has met a number of people with HIV and AIDS. She knows about the basic prevention and transmission of HIV. She has heard about new developments in treatment and wonders if generic drugs taken on a strict schedule could help her patients.

- Harry Benya is a community leader in a village near Freetown, Sierra Leone. There are a number of young people living with physical disabilities in his community. Harry wants to add a classroom to the school and build a ramp so the building is more accessible for these adults. If he knew more about government assistance programs or could improve his advocacy, community organization, and leadership skills, perhaps he could convince the government to provide the funds needed for the construction.

What these individuals have in common is that they could all benefit from using open educational resources (OERs) in formal, informal, and self-learning settings. They are also for- 
tunate to be living in a time when there seems to be a convergence surrounding the importance of education to the cultural, social, and economic development of Africa. In addition, digital technology has opened up unlimited possibilities in communication and education. A greater number of learners now have options regarding what, when, where, and how they learn-circumstances that were inconceivable when most sub-Saharan African countries gained their independence decades ago.

Although the statement "Everyone has the right to an education" (United Nations, Article 26, 1948) was enshrined in the Universal Declaration of Human Rights just over 60 years ago, only recently has there been a concerted effort to ensure that all people have the opportunity to be educated. Education for All (EFA) and the Millennium Development Goals (MDG) have both placed an emphasis on education. EFA, for example, "comprises six interrelated goals that together reflect a holistic concept of educational development" (UNESCO, 2006, p. 1). It acknowledges that education is vital for health and development, particularly for those who are geographically disadvantaged and for women. For example, "every year of secondary education a girl or woman can attain will greatly increase her future income-sometimes by as much as 15\%" (Lake, 2010). If a woman can obtain some postsecondary education, she and her children will be healthier and live longer. Educated women will contribute significantly to the development of their country, thereby helping Africa to climb out of poverty (Bloom, Canning, \& Chan, 2006). Thus, "education is widely accepted as a leading instrument for promoting economic growth" (Bloom et al., 2006, p.1) and good health.

Due to the substantial efforts being made to achieve EFA and MDG goals, there has been a significant increase in the number of children attending primary and secondary schools in developing countries. "Some of the poorest countries have made the greatest strides in education. Burundi, Madagascar, Rwanda...and the United Republic of Tanzania have achieved or are nearing the goal of universal primary education" (United Nations, 2011, p. 5). However, "the population of sub-Saharan Africa's 5- to 14-year-olds is expected to grow by more than $34 \%$ over the next 20 years, and the region will need to respond to the demands of 77 million new students" (Provost, 2011, April 27). Currently, only $36 \%$ of those who want to enroll in secondary education in sub-Saharan Africa can find seats in schools (UNESCO, 2011). In South Africa, for example, 85,000 potential learners applied for one of the 11,000 seats available at the University of Johannesburg (Polgreen, 2012). "Globally, of those 20 or younger, 30 million are qualified to attend university, but there are no places for them. This number increases to 100 million by 2020" (Allen, 2010). "In order to serve the number of youths qualified to enter university in 2020, a major university would need to be opened every week" (Atkins, Brown, \& Hammond, 2007). Thus, the demand for education, especially in sub-Saharan Africa, is much greater than the existing and planned academic institutions can accommodate. In addition, "based on 2004 data, UNESCO estimates that in sub-Saharan Africa alone, 3.8 million teachers will have to be recruited by 2015 if the goal of universal primary education is to be achieved" (United Nations, 2009, p. 16). African governments do not have the financial resources to hire that number of teachers. In fact, between 1991 and 2006, the number of students registered in African higher 
education rose by $16 \%$, but the expenditures to education rose by only $6 \%$ (World Bank, 2010). The demand for educational services is outstripping what countries are allocating to education. In an attempt to rein in the cost of education, several countries, such as Niger, hired "volunteer" teachers (Lambert, 2004) who had no teaching experience and often lacked knowledge of the subject matter they were teaching. In the Republic of Congo, some teachers were not paid for several years (Prozonic, 2011). It does not seem feasible that governments in sub-Saharan Africa will be able to build, staff, and resource schools, universities, and teacher-training facilities to meet the demand over the next 5, 10, or 20 years. The concepts of education for all and equitable access to educational opportunities may not be fully realized. Other educational options, such as the increased use of distance education, information and communication technologies (ICTs), and OERs must be explored for use in traditional and distance educational settings. A combination of different approaches, including the implementation of OERs, can lead to increased accessibility and quality in educational systems within Africa.

OERs are defined as teaching, learning, and research resources with an intellectual property license that permits them to be reused, reworked, remixed, and redistributed (D'Antoni, 2009; Hilton, Wiley, Stein, \& Johnson, 2009; Plotkin, 2010; Wiley, 2009). Some conditions may be placed on the use of OERs, such as the provision of attribution, but all OERs are accessible to anyone. These untapped resources have the potential to reduce costs, improve quality, and increase access to educational opportunities (Daniel, 2011; Plotkin, 2010). Benefits of OERs are outlined below. As these benefits are interrelated, some of the items placed under one heading could easily be placed under another.

\section{Reducing Costs}

A vast number of existing OERs can be accessed, adapted, and used by one or millions of learners, thereby minimizing the costs associated with the acquisition and development of educational resources. Often overlooked is the cost savings accrued to learners who would be able to access free learning materials rather than paying for copyright-protected resources. The high cost of academic texts and learning materials can be a barrier to those in sub-Saharan Africa who want to pursue an education. Thus, students at the University of Nairobi and the Open University of Tanzania have reduced their textbook costs by using AVU OERs that are freely available online.

If existing OERs are used, funds allocated for resource acquisition and development can be reduced. However, there may not be an appropriate OER that matches the needs of a particular education system. An OER may need to be developed or adapted, but it only has to be developed once since it can be distributed to everyone in the system. Duplication of effort is minimized. Resources and efforts can be focused on other endeavours, including making OERs for other subject areas. For example, the Teacher Education in Sub-Saharan Africa (see TESSA, http://www.tessafrica.net/) Project has led to the development of teacher-training materials that can be used and adapted by anyone. Thus, other educators do not have to spend their effort developing the same teacher-training materials from scratch. If they have the expertise, they could develop training materials in other subjects 
and share them with the global community.

Initially, the development of OERs will require financial resources, but over the long term, for the initiative to be viable, it must "meet provider objectives for scale, quality, production cost, margins, and return on investment" (Walker, 2005). The funds used to "prime the pump" might initially come from external sources, such as the African Development Bank (see AfDB, http://www.afdb.org/) or be reallocated from existing funds. Since all educators must keep their material current and update the curricula, funds for these activities can be directed at the development of OERs that are congruent with the new curricula. When OERs are used, the ultimate payoff for the government is that more citizens are educated and able to advance the social, cultural, and economic development of the country. As noted earlier, the more educated the populace, the more income they are able to earn and the healthier they are. The standard of living rises, which is the government's payback for its investment in OERs.

The availability of OERs in the form of textbooks allows institutions and learners to divert funds from the purchase of copyrighted textbooks. If the open textbooks are printed, there will be printing costs, but this amount would be significantly less than if copyrighted material was purchased from a publisher. Even if the textbook was purchased in a digital form from the publisher, royalty fees would still need to be paid. Various organizations, such as the South African Institute of Distance Education (see SAIDE, http://www.saide. org.za/) Open Educational Resources Project and the Community College Open Textbook Collaborative (http://collegeopentextbooks.org/), make available texts that can be edited and customized by instructors. These customized products can be distributed to learners in digital or print form without incurring royalty fees. If bulk printing is required, it can be done locally, thereby supporting local printing companies (West, 2011).

If instructors want to use any copyrighted material in their class or distance education course, they must obtain permission from the owner of the material. This can take time and money. If OERs are used, permission does not need to be obtained; time and money are saved. Funds can also be saved if the cost of transporting materials is minimized. Digital forms of educational materials can be sent anywhere in an instant without incurring the high transportation costs normally associated with the purchase of textbooks or other bulky learning and instructional resources.

Some of the funds that would normally be allocated to the purchase of educational materials could be reallocated. In the higher-education system, funds could be reallocated to provide additional learner support, professional development, and research. In the primary- and secondary-school systems, more teachers could be hired and paid better, thereby addressing the problem of poorly paid teachers who tend to have high absenteeism and diverted attention because they take on second jobs to support their families. In Africa, there is an "inverse correlation between enrollment rate and teachers' salary" (Lambert, 2004, p. 3); as enrollment increased, governments tried to compensate by paying teachers less and hiring volunteer teachers. Thus, the experienced teachers departed and students were taught by less capable individuals. Reallocating resources could assist in alleviating this problem. 


\section{Improving Quality: Promoting a Culture of Sharing}

The quality of education improves when OERs are developed and used because instructors and learners then have access to resources that they were unable to access previously as these resources were copyright protected and/or costly to obtain. They also have access to up-to-date, quality materials and no longer have to rely on decades-old books, some of which were donated to sub-Saharan African schools by charity organizations after the books were no longer useful elsewhere.

OERs can be used by anyone. They are of great benefit both to instructors who lack the time to develop quality resources and to teachers who lack teaching credentials and the knowledge of the subject matter that they are teaching. The resources would be extremely helpful for the large number of voluntary, inexperienced, and unqualified teachers in sub-Saharan Africa. OERs can also have an impact on the quality of teaching and learning in traditional classes and distance education courses simply by being available. The freely available OERs can be used directly in class, but just their presence exposes teachers to new information and different ways of approaching a subject. By "looking over the garden wall," instructors can reflect on what they do and be inspired to change their instructional methods and the content they present. They can improve what they are doing by seeing what others are doing.

OERs are often developed in a collaborative manner and peer reviewed by international experts. Thus, various people are involved in constructing OERs within the quality framework set by the institutions and organizations for which they work. This process involves people reviewing the curriculum, searching for suitable material, deciding what needs to be built, then contributing their expertise to the development and refinement of the finished product. The resulting product, formed through a diverse intellectual exchange, is usually substantially better than one produced by a single individual. This collaborative production model for OER development restores "the core values of building and sharing knowledge that underpin good education and systematically encouraging us to work with and learn from one another" (Butcher, 2011, p. 45). The successful collaborative processes used during the development of courses and programs offered by the African Virtual University (see AVU, http://www.avu.org/) and the University of Mauritius (see UoM, http://vcampus. uom.ac.mu/) could be employed by other African educators and institutions.

Since OERs are published for all to see, viewers worldwide, including students and employers, can comment on the quality of the items and provide feedback. The extensive feedback can be used to improve the educational resources and promote educational excellence.

Multiple representations of concepts can be presented to and be used by learners. If learners have difficulty understanding a particular topic, they can seek an OER that explains the concept in a different manner. If learners adapt an OER to meet their needs, they become more actively engaged in learning. Furthermore, their revised OER can be made available to others who may have encountered similar difficulties, thereby perpetuating a culture of sharing, which lies at the foundation of the OER movement. OERs can be adapted to ad- 
dress local needs and the cultural context in which they will be used.

If students have access to OERs, then face-to-face instructional time can be focused on discussion, debate, and practical applications. These types of engaging activities promote the development of $21^{\text {st }}$-century skills such as critical thinking, creativity, and problem solving. Learners could also use OERs for self-learning. OERs have

the potential to change the practice of learners, educators, and organizations in a profound way. The learner is given choice by OER of ways to learn, either as existing courses make use of the resources or much less formally through individual or group learning around and with the open sources. (McAndrew, 2010, p. 125)

\section{Increasing Access}

OERs are based on the premise that knowledge is created by society and should be shared for the benefit of society. Thus, knowledge should be freely available to help people learn and to facilitate lifelong learning. In practical terms, educational resources produced by public funds should be made available to everyone so that all may benefit.

OERs can be used by anyone, at any age and at any time. They can be used by those who are registered in an academic course or program and by those who just want to improve their knowledge and skills to solve a problem or learn for the pleasure of learning. Some will use OERs to help them attain entrance into an academic institution or to obtain credible postsecondary credentials from recognized educational institutions through the OER University (see OERu, http://wikieducator.org/OER university/Home). This latter institution aims to provide a viable and sustainable alternative for learners who are unable to attend traditional courses or programs. Some individuals will use OERs to help them learn a skill they need for their work or to address problems in their personal lives. OERs can be used to help people build their own learning paths.

A number of people can access digital OERs simultaneously. Thus, one resource can serve many, including those within and outside of the classroom. OERs can be used in traditional, open and distance learning, and self-learning situations. Learners and instructors who lack core or supplementary learning or instructional material can find, adapt, remix, and use OERs that are congruent with their learning or instructional objectives.

OERs can serve those who may be geographically or financially disadvantaged. However, it must be acknowledged that given the current lack of ICT infrastructure in Africa, the disparity between the haves and have-nots may be highlighted. To the have-nots, OERs may not be open and free. Learners and instructors who want to use digital OERs need access to a computer and compact discs or the Internet, but they do not have to personally own a computer. They can access both a computer and the Internet at a friend's home, at computer learning centres being established by communities and institutions, or at the increasing number of Internet cafés. In time, some OERs will be accessible via mobile phones, 
which are ubiquitous in sub-Saharan Africa. Although it may be a challenge for some people in Africa to access online OERs, the resources are still freely available online and could be distributed in print and compact disc formats that are accessible to many.

If individuals have access to a computer and the Internet, they can gain access to global resources that were previously out of reach and thus increase their chances of finding materials that meet their specific needs. Most countries in the region have a national ICT plan that will lead to more equitable access to the Internet and global resources. At the Connect Africa Summit: Bridging the Digital Divide (2007), 43 African governments agreed to "connect villages to broadband by 2015, adopt key regulatory measures that promote affordable, widespread access to ICT services, (and) support the development of a critical mass of ICT skills" (UN Economic Commission for Africa, 2007). "The introduction and use of appropriate ICT solutions can and does contribute to socio-economic development and helps to create opportunities for people to shape their own individual future and that of society around them" (International Institute for Communication and Development, October 24, 2011, p. 3).

If OERs were available and accessible, the individuals mentioned at the beginning of this section-Grace, Bethel, Sunday, Rebecca, and Harry-would have access to the information they require in formal, informal, and self-learning settings. They would be better able to develop skills and make decisions that will benefit themselves and those around them. Grace, for example, would benefit from accessing teaching materials from TESSA. Bethel, the secondary-school student, could improve her mathematical skills if she had access to the free videos from the Khan Academy (see http://www.khanacademy.org/). The resources available from the OER Africa (see http://www.oerafrica.org/) AgShare Project might be useful to Sunday, the farmer, and Rebecca could learn more about HIV/AIDs from the resources offered by the OER Africa Health Network. Harry, the community leader, could gain access to leadership materials from OpenLearn (see http://openlearn.open.ac.uk/) at the Open University in the United Kingdom, but it would be most helpful to Harry if the government provided online access to its assistance programs.

The successful development, distribution, and use of OERs in sub-Saharan Africa will require government and education leaders to face a number of challenges. The challenges below are discussed in greater detail later in this article.

- Creating and sustaining an institutional, national, and/or regional vision for OER development and deployment that embraces a culture of sharing

- Developing and distributing resources with an open license and ascertaining the effect this will have on current intellectual property policies and procedures

- Improving the technology infrastructure and reducing the cost of Internet access in order to achieve equity of access

- Establishing communities of educational collaborators to develop and use OERs

- Sustaining involvement in the OER initiative so that it can be continued once initial ex- 
ternal funding is reduced or eliminated

- Producing resources in interoperable and open formats that are freely available or easy to obtain

- Establishing and maintaining the quality of the resources by setting standards and allowing for mass peer review

- Providing local context so that the materials address national and regional needs and conditions

- Informing the public about OERs and educating the users about how to locate, evaluate, and utilize OERs so that they may be empowered to make decisions about their lives

- Taking the initiative to build on the knowledge, skills, and experiences of others, thereby minimizing the duplication of effort and reducing the learning curve

\section{The Next Step}

In order to pursue the goal of education for all and provide learning opportunities for all Africans, including the five individuals described at the beginning of this section, government and educational leaders must have the collective will and commitment to innovate and take the opportunity to grasp the potential of OERs. They can build on OER success stories achieved by AVU, OER Africa, SAIDE, the Virtual University for Small States of the Commonwealth (see VUSSC, http://www.vussc.info/), and other African and global OER initiatives. But in order to do so, they must address the challenges listed above. The next section of this document provides an in-depth discussion about the challenges associated with the development and use of OERs and what should be considered in advancing the OER movement in sub-Saharan Africa.

\section{Looking Forward}

As can be discerned from this document and others in the academic media, OERs have the potential to increase accessibility to quality educational materials at a lower cost to the user, thereby allowing governments and institutions to divert funds to other critical areas, such as learner support, faculty professional development, research, and teacher recruitment and retention. OERs enable individuals to freely access information they can use to make decisions that affect their lives and ultimately the progress of societies. OERs also have the potential to allow for flexible, quality education through distance learning and to assist most African countries to meet the increased demand for secondary and higher education. But can this potential be realized in sub-Saharan Africa? Looking forward, what are the challenges that must be overcome to fulfill the potential of OERs in sub-Saharan Africa? A number of challenges that face the OER movement in Africa are discussed below; many of them may also apply to the development and use of OERs in other areas of the world that have weak economies. Although the items below are listed as discrete entities, many are 
interrelated and affect one another-the decisions made about one entity may affect the decisions regarding a second entity. Note also that statements made in this article may not reflect the full spectrum of educational development within Africa; thus, some suggestions may not be applicable to some regions of sub-Saharan Africa.

\section{Creating and Sustaining a Vision for OER Development and De- ployment in sub-Saharan Africa}

Governments and educators in sub-Saharan Africa are faced with an increased demand for education, yet their countries' weak economies make it difficult to support their educational endeavours.

In most sub-Saharan African countries, enrollment in higher education has grown faster than financing capabilities, reaching a critical stage where the lack of resources has led to a severe decline in the quality of instruction and in the capacity to reorient focus and to innovate. (World Bank, 2010, p. xiv)

However, governments are fully cognizant of the impact education can have on social and economic development. For example, "educated girls are less likely to marry or have children early; they are better able to protect themselves from HIV and AIDS and from sexual exploitation and abuse" (Lake, 2010). "Education and health (can) increase human productivity, raise life expectancy, and facilitate community life. They have a major impact on economic growth and increase individual and collective well-being” (Diagne, 2006, pp. 3-5). Thus, education is paramount if countries with weak economies are to get stronger.

But how can the quality of and access to education be improved with minimal financial resources? As Sir John Daniel (2010) asked when he introduced his concept of the iron triangle, is it possible to increase access, improve quality, and cut costs all at the same time? One possible way to achieve this is through the development and deployment of OERs because they are freely available and can be accessed for formal and informal purposes and because the collaborative approach to their development and deployment decreases the cost per student and improves quality.

If the only focus for employing OERs is the reduction of cost per student then the true potential of OERs to contribute to the improvement of education will not be realized (Butcher, 2011). The current approach to OER development and distribution involves collaboration among the creators and users, who work together to develop and revise educational material. For this approach to work effectively, all must believe that the sharing of knowledge and experience lies at the core of academic activity (Lerman, Miyagawa, \& Margulies, 2008). It is during this sharing and curriculum-mapping process that educators ascertain the priorities of other instructors and learn about the content they are teaching and the approaches they are using. Consequently, educators learn from this experience and can apply it to their own situation. The education system will improve incrementally at first. As the collabora- 
tion proceeds, there is greater potential for the education system to change dramatically and to provide the knowledge and skills students need for the $21^{\text {st }}$ century. The open, creative, collaborative process "enables continuous rapid improvements in the quality of both teaching and learning” (Plotkin, 2010, p. 1).

Government decision makers and leading educators can set out a powerful vision for their educational system by emphasizing the importance of education to social and economic development and the key role that education and OERs can play. The use of OERs can reduce educational costs, promote collaboration, increase access to up-to-date, quality educational materials, and cause educators to reflect on and improve their current practices. Governments can set the policies and priorities for OER development by

- actively advocating for the use of OERs, addressing the various myths and barriers to OER use, such as the "not-invented-here syndrome," and providing case studies of successful OER development and deployment in Africa;

- promoting a culture of sharing and stressing the need for institutions and educators to work together; thus, future funding initiatives should involve two or more institutions;

- including OERs in national ICT policies and plans;

- mandating that all resources produced by public funding be accessible to all;

- encouraging the use of open formats and open license;

- facilitating a review of curricula offered by institutions in the country in an effort to determine common areas that could benefit from the development of OERs;

- making it easier for educators to know what resources are available;

- encouraging educators and governing bodies at institutions to discuss OER development and deployment at the same time that they discuss financial, technical infrastructure, and personnel requirements; and

- keeping informed of the global OER movement through linkages with international organizations.

Additional suggestions for the role of government in OER development and utilization can be found in the UNESCO-COL (2011) publication Guidelines for Open Educational Resources (OER) in Higher Education. Note that suggestions for the development and implementation of OERs may differ between public schools and postsecondary institutions. Governments may dictate how OERs are developed and used in public-school systems but often are able only to provide guidance at the postsecondary level as tertiary institutions tend to govern themselves and professors tend to have more freedom to select and develop resources than teachers do. 
If the vision for OER development and deployment in Africa is to be sustained and achieved, it will be necessary to

- establish achievable goals that address the needs of the institution, educators, learners, and the community;

- conduct an analysis of strengths, weaknesses, opportunities, and threats (SWOT analysis) associated with the use of OERs and build on the work of AVU, TESSA, OER Africa, and similar OER initiatives;

- ascertain the benefits of the use of OERs and question what would occur if OERs were not employed, for example whether the cost of education would increase at the same rate and whether informal and formal access to education would increase;

- obtain the support of educators for the use of OERs and address their concerns, especially those related to intellectual property;

- convince educational stakeholders such as instructors, learners, parents, and employers about the merits of the vision; clearly indicate to institutional personnel what is gained and what may be lost by using OERs; build consensus on the way forward;

- identify educational leaders and institutions who could advance the vision; consider those who are currently involved with OERs and assess whether their expertise is recognized by others so they can take on a leadership role; identify those who are committed to innovation and are politically astute;

- consider employing the consortium program model (Diallo, Wangeci, \& Wright, 2012), which highlights collaborative planning, decision making, and OER development across educational institutions that may have different political, geographical, cultural, and language backgrounds, but all share a vision to address the needs of their learners;

- develop action plans that specify the criteria of success and timelines to be followed; start small by having a razor-sharp focus on one portion of the curriculum at a time rather than using a "scatter" approach to please as many stakeholders as possible, but in the end pleasing no one with the quantity and quality produced; allow sufficient time for collaboration as this can seem slow at first but with experience can become efficient and lead to a better product;

- $\quad$ assign tasks, state accountabilities and deliverables, and specify resources to be provided;

- ascertain barriers that need to be overcome and address them;

- provide support and training;

- monitor the implementation of the vision and make adjustments as required; 
- publish the progress of the implementation so that all stakeholders can be informed and be acknowledged for their efforts, thereby sustaining their participation;

- assess the outcomes of the initiative and note any unexpected outcomes that should be taken into account during future stages of OER development and deployment; and

- provide effective leadership that sets high standards, takes into account the attributes of the participating organizations/institutions, is open to suggestions, and is flexible yet decisive (although authoritarian approaches to leadership may be effective elsewhere, educational collaboration requires a more flexible leadership style that focuses on team rather than individual effort).

In order to accomplish the above, it may be helpful if African education and government leaders participated in an OER workshop and completed modules about the benefits and challenges of OERs as well as about their effective implementation-a workshop and module format similar to the successful Academy of ICT Essentials for Government Leaders developed by the United Nations Asian and Pacific Training Centre for Information and Communication Technology for Development (see APCICT, http://www.unapcict.org/). This APCICT initiative was designed to harness ICTs for socioeconomic development. In the future, it is expected that OERs will be discussed along with ICTs.

By creating an achievable vision, assigning those with a passion for OERs and their potential to the OER initiative, allocating or reallocating resources, and establishing institutional, national, and pan-African leadership linked to the global OER movement, it will be possible to improve African education at a minimum cost over a period of time.

\section{Developing and Distributing Resources with an Open License, thereby Increasing Access and Lowering the Cost of Obtaining Educational Resources}

The world is overflowing with an abundance of educational material. Nevertheless, many African educators and learners do not have access to it and may have limited access even to resources produced within their own country. The resources are likely to be inaccessible due to the cost of the material, shipping charges, and copyright restrictions. It can be a challenge for the following people to obtain learning resources: a primary-school teacher in the Republic of Congo earning US\$40 per month, an upper-primary school teacher in The Gambia taking home US $\$ 85 /$ month, a high-school instructor in Sierra Leone making US $\$ 175 /$ month, and a lecturer at Makerere University in Uganda earning US\$390/month (Kavuma, 2011). If teachers are unable to afford learning resources, it is even less likely that students will be able to obtain them.

Copyright is one of the main reasons that educational resources are inaccessible to and/or expensive for learners and teachers in Africa. Even if instructors can obtain the material, there are often restrictions on its use. For example, instructors may not be permitted to make copies for their students, modify the material to suit their pedagogical approaches, or place the resources online so that more people would be able to access them. In most coun- 
tries, the original author, producer, publisher, and/or distributor retain full copyright of the materials they produce. Consequently, individuals who want to use the work must seek permission from the author or producer. This process takes time and costs money. If the resources are produced with an open copyright license or if the creator clearly states that the material is freely available for use in any form, then users can access the resources without seeking permission or paying royalty fees. Only in a few countries, such as Canada and the United States (which have "fair use" or "educational use" provisions in their copyright laws), can educators use a portion of the material without seeking permission.

Open copyright licenses enable others to use, replicate, adapt, and remix resources without seeking permission or paying a royalty fee. Creative Commons is an organization that provides a legal licensing framework that enables creators to retain the copyright for their work yet allows others to copy and distribute it. The creator may also dictate how the material can be used, modified, or remixed, whether the creator of the material must be identified, and whether the material can be used for commercial purposes. OERs have open copyright licenses, and many OERs have a Creative Commons license that operates within the copyright laws of the country in which copyright is granted.

If educational institutions were encouraged to use resources with an open copyright license and if resources produced by the government and by government-sponsored or supported entities, such as educational institutions, were released under an open copyright license, then institutions could reduce the time and the funds they spend on obtaining resources. Obviously, users of these resources would need to set aside funds to print the resources or to have them duplicated on a compact disc (CD) or digital video disc (DVD). If the resources were available in a digital form and could be accessed online, funds for printing and conversion to a disc would not be required.

Since OERs have open copyright licenses, they can be used, copied, and distributed by citizens everywhere. As noted above, there may be restrictions regarding use, modification, and/or remixing, but many OERs have no restrictions of any kind. If African institutions used OERs, the cost of instructional and learning resources would be significantly reduced. If educational institutions were required to release material under an open copyright license, then public institutions could easily share the resources they produce. As there are a number of for-profit organizations and private educational institutions in Africa that are not publicly funded, a decision must be made as to whether these institutions can use OER materials. Ideally, all institutions should be able to use OER materials, and private institutions should be encouraged to participate in the production of OERs. As the use of OERs by private institutions can be a lightning rod, this situation must be dealt with quickly and decisively.

In order to accrue the benefits associated with OERs, African nations should seriously consider developing and distributing educational and government material with an open copyright license. Perhaps open copyright licenses should be applied by default to any materials produced by public funds (UNESCO-COL, 2011). Thus, publicly funded material could be studied in relevant courses, and the activities of the government would be more transpar- 
ent. However, guidelines would need to be established for determining why some publicly funded resources should be exempt from open copyright provisions. Also, contracts and job descriptions of those paid by public funds would need to include a provision specifying that a person's work product could be released under an open copyright license.

Educational institutions could be encouraged or required to share their instructional and learning resources. It is a duplication of effort if each institution makes, for example, the same drawing of a four-chambered human heart. But it is acknowledged that the detail and labelling of a heart diagram to be used in a junior secondary school will be different from one used in a postsecondary institution. Regardless of which institution makes the diagram, it should be released under an open copyright license so others can use it without cost. The heart diagram could be combined with other diagrams of the human body to make one integrated OER. If the diagrams are obtained from different sources with different restrictions regarding their attribution or use, institutions need to track these restrictions and inform users of them.

Requiring personnel at educational institutions to release their learning and instructional materials with an open copyright license can be a challenge to implement in countries where teachers are paid poorly. In these countries, teachers may sell compulsory handouts or their lecture notes to students in order to earn extra income, thereby significantly increasing the cost of education to learners. By publishing materials openly, instructors may be unable to sell their lecture notes. But is it right for instructors to sell information that they should be delivering during class time to students registered in their course? Is it right to charge students additional fees when many experience difficulties with paying basic educational fees? Furthermore, shouldn't the duties of instructors include providing students with up-to-date information?

Instructors may also resist the implementation of the open copyright provision because the quality of their work will be exposed for all to see. Those who use incorrect information, outdated content, and plagiarized material will be uncovered. Issues regarding the quality of OERs will be discussed later in this document.

\section{Improving the Technology Infrastructure and Reducing the Cost of Internet Access}

The successful development, distribution, and utilization of OERs depend on access to reliable electrical power, reasonably priced Internet services, and appropriate hardware and software. These conditions apply not only to OER development and deployment, but also to educational systems of the $21^{\text {st }}$ century.

In Kenya, only $65 \%$ of the secondary schools are connected to the power grid (Ngare, 2007), and only $3 \%$ of the 6,566 secondary schools have Internet connectivity (Kiptalam \& Rodrigues, 2010). However, all higher-education institutions in Kenya have electrical power and Internet connectivity. This level of access to electricity and the Internet can be seen throughout most of sub-Saharan Africa. 
As access to uninterrupted power is limited in sub-Saharan Africa, institutions and individuals often rely on relatively expensive diesel- or gas-powered generators to produce electricity. SchoolNet Namibia has achieved some success with the use of solar and wind power, and it is expected that other educational jurisdictions may embrace these forms of alternative energy. Until electrical power is more widely available at a reasonable price, users will need to obtain ICTs that consume little energy or have built-in electrical generating devices. For example, the Intel Classmate PC computer uses low-powered electronic processing chips, the Samsung NC215S laptop has a solar panel built into the laptop cover, and models of the One Laptop Per Child (OLPC) computer have auxiliary power-generating devices, including solar panels.

Although OERs can be distributed via CDs, DVDs, and print to allow for offline access, they are more commonly accessed online. Only $11.4 \%$ of Africans have Internet access compared to a world average of $30.2 \%$ (Internet World Stats, 2011). Internet penetration in sub-Saharan Africa is limited because of cost and lack of access. The cost of obtaining mobile and Internet services in Africa varies widely, relative to the cost of staples such as tea and sugar (Calandro, 2011).

In about half the countries in Africa, one year of Internet supply will cost more than the average annual income... In only five countries-South Africa, Botswana, Tunisia, Mauritius, and Libya-is the annual cost less than $10 \%$ of the average income. (Hesselmark, 2010)

In an effort to provide increased global connectivity for the African continent and address the lack of Internet supply, several undersea cables, such as the South Atlantic 3/West African Submarine Cable (SAT-3/WASC) system, have been planned or recently deployed (see http://manypossibilities.net/african-undersea-cables/). As the number of submarine optical cables connecting Africa to the rest of the world increases, Internet costs will decrease and bandwidth will increase. Thus, Internet subscriptions will increase. Note that Chad, the Democratic Republic of Congo, Eritrea, Guinea, Liberia, Seychelles, and Sierra Leone do not have a fibre-optic connection and rely on expensive satellite links (Craddock, 2011). Landlocked countries lack easy and inexpensive access to submarine cables. Even if African countries had access to optical cables, Internet prices may not decline due to the lack of local hosting and interconnection within Africa. Most Internet traffic is routed through Europe and the United States. There is a need to interconnect African countries efficiently, to establish mirror servers containing educational content that can be downloaded locally, to reduce the cost of connectivity by compressing data before it is sent (Trucano, 2011), and to establish a healthy competitive environment for the telecommunications industry (Thornton, 2008). In several African countries, only one or two companies are permitted to provide Internet access to local service providers. Normally, three or more companies are needed to ensure a competitive marketplace for Internet services (Gross, 2006; Hesselmark, 2010). Initially, governments may decide to establish public-private ventures to address the digital divide, but the private sector, through various "carrot and stick" ap- 
proaches, should ultimately assume primary responsibility for developing the infrastructure. The government should not be the sole provider of Internet services.

Computers are the usual means by which educators and learners connect to the Internet. Access to computers "is a major challenge facing most African countries, with a ratio of one computer to 150 students against the ratio of 1:15 students in developed countries" (Kiptalam \& Rodrigues, 2010, p. 50). In Africa, these devices are still expensive relative to income. In Kenya,

a country with a GDP of $\$ 1,600$, the majority of the individuals and schools cannot afford to buy a computer and consider it as a luxury item, more expensive than a TV. While second-hand computers cost as little as $\$ 150$ and brand-new computers (are) being sold at $\$ 500$ or higher. (Mungai, 2011)

An inexpensive computer such as India's subsidized \$35 Aakash tablet, which "is adequate for most applications including HD-quality video, reading books, and basic office applications" (Ribeiro, 2011), may be appropriate for use in sub-Saharan Africa provided it is reliable and capable of performing the tasks desired by African educators at a speed that does not frustrate users. African educators could also make greater use of second-hand computers refurbished by organizations such as Computers for Schools Africa (see http:// www.cfsk.org/). Whatever technology is used, it must be affordable to the population who will use it, it must be supported and maintained, and people must learn how to use it. These conditions exist whether or not OERs are deployed in an educational system.

A consensus seems to have formed that the introduction and use of ICT in education can help promote and enable educational reform, and that ICT is a useful tool to both motivate learning and promote greater efficiencies in education systems and practices. (Trucano, 2007)

The development and deployment of OERs via ICTs will also lead to efficient and effective educational systems and practices.

Mobile phones seem to be ubiquitous in Africa as mobile coverage reaches $90 \%$ of the population in many developing countries (World Bank, 2006). By 2015, more people in sub-Saharan Africa will have mobile phone network access than electrical access in their homes (Ali, 2011). In time, perhaps mobile phones will be the solution to expensive Internet connectivity and will provide economical access to digital material. Currently, the BridgeIt initiative in Tanzania enables teachers at 150 schools to use mobile phones to download short videos from a central server to a local television set (Kasumuni, 2011). However, most phones used in Africa are not smartphones, so they are unable to download content from or upload content to the Internet and lack features such as the Siri voice-activated personal assistant found on the iPhone. Furthermore, the bandwidth available for each mobile phone 
is often limited. But current mobile phones can be used by learners to access prerecorded educational audio messages and audio-based OERs and to communicate via voice or text with other learners and instructors.

Due to the challenges associated with limited bandwidth, Internet connectivity, and the cost of hardware and software in sub-Saharan Africa, OERs are likely to be designed to fit within a small digital file and be distributed in paper form. Hence, the full potential of interactive, engaging OERs may not be realized until an increasing number of educators and learners gain access to reliable Internet services at reasonable prices. Furthermore, digitized forms of OERs may be more accessible to only a portion of the population, thus increasing the gap between the haves and the have-nots-a situation that should be minimized if the goal of education for all is to be achieved.

AVU has attempted to alleviate concerns regarding access to ICTs by establishing 10 Open, Distance, and eLearning (ODeL) Centres in countries such as Ethiopia, Kenya, Senegal, Zambia, and Zimbabwe. These centres "act as physical hubs for the creation, organization, and sharing of knowledge, as well as the development, delivery, and management of ODeL programs at AVU Partner Institutions" (African Virtual University, 2011a). The centres enable educators and students to access, develop, modify, and remix OERs. Each centre functions as

- a training facility for Partner Institution staff in the use of ICT in the development, delivery, and management of open, distance, and e-learning (ODeL);

- a delivery point for current and future ODeL programs (e.g., the Teacher Education Program);

- a physical location where staff are able to conduct research and participate in collaborative work in ODeL; and

- a revenue-generating facility with the goal of guaranteeing long-term sustainability (African Virtual University, 2011a).

Similar learning centres are being established by African governments and other organizations such as the Southern Africa Development Community (see SADC, http://www.sadc. int/), which has established centres in Malawi and Tanzania. The Rwandan government has established 12 telecentres and 2 mobile ICT buses to help those in rural communities develop, adapt, and share information online as well as to facilitate skill development, create employment opportunities, and enable individuals to market their products online. But there are not enough centres to meet the needs of those who lack access to ICTs, and few centres are located in rural areas. If OERs are to be more widely used, this situation must change. Whether OERs are developed or not, access to ICTs is an essential ingredient of modern educational systems.

Many countries, such as Kenya, Botswana, and Zimbabwe, have national plans and policies for ICT implementation. Kenya, for example, plans to provide an ICT infrastructure 
for all of its 6,000 secondary schools (Sunday, 2012). However, these ICT implementation plans have often been carried out slowly due to lack of resources and/or competing priorities. People will benefit from clean drinking water, improved sanitary conditions, improved health services, and increased agricultural production, but they will also benefit from having access to ICTs that will help them obtain clean drinking water, increase agricultural production, and so forth (Wright, 2010). Government, education, and community leaders need to act on the ICT plans they have already developed. When the plans are being updated, OERs should be included.

\section{Establishing Communities of Educational Collaborators to De- velop and Use OERs}

OERs are new to many people in Africa. They must be convinced of the benefits of sharing OERs. But they should also be aware of the myths and fears associated with OER use. According to Anderson (2009), some of the myths that must be dispelled include those below.

- My job is to create original course content, so I can't use materials produced by others. (Isn't sharing knowledge at the core of academic activities?)

- My course/content/context is so different that I can't use external resources. (As mentioned previously, is it necessary to duplicate effort by producing another diagram of a four-chambered heart?)

- It is harder to contextualize materials made by others; it's easier to create my own. (Does it really take longer to adapt someone else's textbook than to write your own?)

- If I put my course materials online, someone will steal them (But of course, I never borrow from someone else).

Instructors must be convinced that sharing and collaboration have the potential to reduce workload over the long term, as everything will not need to be developed from scratch.

Some people may fear the use of OERs and the application of ICTs in education. A few of these fears are outlined below, and each must be addressed.

- Fear of the unknown. This is common to any situation that causes a change to an individual's routine. Educational leaders may be concerned about making decisions involving technology that they know little about and may not want to admit to others that they don't know anything about OERs and ICTs. Knowledge and skills about the production and use of OERs seem to be inversely proportional to rank (Plotkin, 2010, p. 4).

- Fear of losing their jobs. Instructors may feel that they will be replaced by OERs and ICTs. Often, to sell the cost of implementing OERs and technologies, politicians may say that by introducing ICTs, fewer instructional staff will be required. These types of statements were made during the eLearning Africa Conference in Nairobi in 2007. The addition of technologies should not lead to the elimination of teaching staff, but should 
simply lead to a change in their roles.

- Fear of being made irrelevant. Instructors want to be seen as the authority or "knowit-alls," so anything that may lead others to think that they are not is not supported (Mungai, 2011).

- Fear of being found out. This fear is related to the one above. If instructors are required to release their materials under an open copyright license, then others will be able to see the quality or lack of quality therein. Any lack of knowledge will be exposed. All educators need to come to grips with the fact that they don't know everything about a particular subject. In order to learn, they, like their students, must be challenged to learn.

- Fear of a level playing field. If instructors at all institutions can access and use the same OERs, then everyone will be at the same level. How can institutions differentiate themselves? There is more to obtaining an education than having access to the same content. Many institutions use the same textbooks, but they differentiate themselves and gain competitive advantage by how they help learners gain and apply knowledge and skills to solve current and future problems.

Instead of dwelling on these myths and fears, educators need to ask different questions, such as how can I use my time and expertise more effectively? They also need to be surrounded by like-minded professionals who discuss similar questions and are focused on improving the education offered to their learners. Rather than try to convince everyone to use OERs or to impose OERs across an institution, educational leaders should focus on those who are willing to develop and use OERs, especially those within a particular program. This approach is recommended for introducing any technology in higher education (Bates \& Sangrà, 2011) and has merit when implementing any change-go with the willing. As the benefits and success stories about OERs become more widespread, others will join the OER movement. The inertia of resistance to change will be overcome.

Like-minded individuals who want to embrace positive improvements to the current educational system could establish communities of practice to support the development and deployment of OERs. Perhaps an OER community of practice could be based on the model used by AVU to help its Partner Institutions design, develop, deliver, and manage their own open e-learning programs. The AVU Capacity Enhancement Program (ACEP) has led to a community of practice for open and distance learning (ODL) development in 10 countries. The objectives of the program include

- working effectively in multidisciplinary teams on issues related to open and distance e-learning (ODeL) program development, delivery, and management;

- developing ODeL projects integrated within their respective culture and institutional context; and

- participating in a community of practice focused on the respective roles and responsi- 
bilities in three streams: governance, technology development and support, and materials development and instructional design (African Virtual University, 2011b).

AVU has a formal basis for its community of practice as those registered in the program must participate in workshops, complete 13 modules, and prepare project proposals for ODeL. All participants must be willing to train other academics at their respective institutions.

AVU and the African Development Bank have also launched the Teacher Education Virtual Consortium (TEVC), which provides a collaborative approach toward developing content for four bachelor of education programs. The consortium has several objectives, including

- developing African-based teacher education content that could be in an OER format;

- building a teacher education community of practice that cuts across language barriers and national boundaries;

- strengthening quality assurance mechanisms; and

- facilitating staff mobility and the capability for students to transfer credit amongst members of the consortium (African Virtual University, 2011c).

Similar consortiums could be established for the development of materials in other subject areas. For example, the Commonwealth of Learning (see COL, http://www.col.org/) and the William and Flora Hewlett Foundation (see http://www.hewlett.org/) have recently completed the development of OERs in a self-study format for 20 selected subjects at the secondary-school level. These resources were developed by educators from Botswana, Lesotho, Namibia, Seychelles, Trinidad and Tobago, and Zambia. The OERs produced by the more than 100 educators are available for others to use.

Ideally, sub-Saharan governments and educational leaders could agree on a broad curriculum framework that would encourage the acquisition and development of OERs for different educational levels, such as primary, senior primary, junior secondary, secondary, graduate, and post-graduate. The goal of this initiative would be to identify and develop OERs that could be used at specific levels within educational systems in Africa. As each country has different expectations for the different levels of their education system, the goal of this initiative would not be to dictate what curricula should be taught in each country. Rather, the goal would be to identify, locate, and/or develop common resources that are needed by all countries. Then, educators in individual countries could use a program such as OERGlue (see http://www.oerglue.com/) to gather resources, add interaction, and build courses for a local audience. Educators could also adopt the five-step development process often used by those involved in VUSSC development projects: find, compose, adapt/repurpose, use, and share. However, prior to conducting a search for OERs, educators should carefully consider their instructional/learning intent as well as the pedagogical and/or andragogical needs of their potential learners. 


\section{Sustaining Involvement}

Once the OER initiative has gained momentum, how does one sustain it over the long term? "Sustainability points to the need to ensure that OER initiatives become embedded in policies, structures, and programmes to extend learning opportunities and knowledge sharing " (D’Antoni, 2009, p. 7). Sustainability also depends on a number of interrelated factors such as funding, technical considerations, content, and staffing (Downes, 2007). In addition, one must consider the cost of covering communication and travel expenses, producing new OERs, updating existing ones, and providing training to those who produce and use them.

Ultimately, any initiative can be sustained if the reason for its existence is well understood, it has a significant impact on people's lives, and participants are willing to contribute their time, expertise, resources, and/or funds to maintain it. Wikipedia is an example of a project that has been sustained primarily by voluntary help but the organization also needs some baseline funding. Obviously, a large infusion of funds can help to sustain any initiative. But as is the case for a number of exciting projects in Africa, once the initial funding from an overseas organization ceases, the local projects are likely to wither away. At the inception of any project, the sustainability of the project must be discussed, and locals must have a stake in the project so that once external funding is reduced or terminated, there is still interest in seeing the continued growth of the initiative. People usually value and monitor what they have a stake in and what they pay for.

Stephen Downes (2007) suggested a number of financial models that could be used to sustain OER initiatives. Each model is very briefly outlined below.

- Endowment - Funding is sustained by interest earned on a base fund.

- Membership - Members contribute a specified sum of money and receive services.

- Donations - Donations received are managed by a nonprofit foundation.

- Conversion - Something is given away. Then users are convinced or converted to paying for additional features or something else.

- Contributor pay - Contributors pay the cost for maintaining the program.

- Sponsorship - Companies support the initiative in return for advertising or public relations.

- Institutional - An institution assumes responsibility for the initiative.

- Government - Direct funding is received from the government.

- Partnerships and exchanges - Items are exchanged between partners.

Combinations of all of the above models could be employed in sub-Saharan Africa, but some will meet with greater success than others. For example, the sponsorship model could 
work if the focus is on public relations. If the focus is on advertising, the challenge would be to ascertain the value of the true market size and to determine whether there should be commercial advertising within institutions. Any financial model that requires the collection of a fee from individual users, such as learners, can be expensive to maintain even when mobile phones and microfinancing software are used. Furthermore, can individuals afford to pay for the resources, especially those seeking an informal education, as they need to update their skills in order to seek employment? Whatever price may be set to access OERs must be small and affordable to the users and take into account the different lengths and complexities of the downloaded material. If funding is received from governments, then it should be allocated over an extended period of time so that those involved in OER development and deployment can plan effectively.

Below are some suggestions that governments and institutions could use to sustain the development and deployment of OERs in Africa.

- Assign leaders to the OER initiative who have a passion for improving education and actually know about OERs, ICTs, and ODL.

- Revise or develop institutional policies that reward collaboration, OER sharing, and OER development. OER development could be recognized at the same level as research or the submission of an article to a referred journal. To receive this level of recognition, the OER must be peer reviewed, have a significant impact on learning, provide a new approach to the subject matter, and/or attract attention or funding from other educators.

- Assign copyright of resources produced by individuals working at public institutions to the institutions, or have the resources assigned with an open copyright license. If this action is taken, this condition of employment must be clearly stated in employment contracts.

- When a particular curriculum is reviewed, educators should be required to identify OERs that would support the course or program. If suitable material is available, funding to develop new resources would not be provided.

- Place a priority on projects that involve two or more individuals within an institution and two or more institutions within a country or region.

- Make cascading training standard operating procedure so that when an individual receives training about the development and use of OERs, he or she is contractually obligated to train at least two other people. Training or professional development about OERs must be built into any OER initiative.

- Build OER development and use into existing ICT integration initiatives such as the Flexible Skills Development Community Learning Network (see http://flexibleskillsdevelopment.ning.com/), which focuses on using technology to facilitate flexible and quality teaching and learning in technical and vocational programs at 10 polytechnics 


\section{in Africa.}

Compared to the salaries of similar professionals, instructor salaries at many African institutions are low (Wolfenden, 2008). Thus, the above suggestions may need to be supported with other measures. If instructors need to support their families by taking on additional paid employment, as $74 \%$ of the teachers do in Cameroon (Lambert, 2004), then recognition for a "job well done" may not be enough-additional incentives may be necessary as outlined below.

- Consider the production of OERs in job promotions.

- Pay for a professional development opportunity that the instructor may not be able to afford on his or her own. This opportunity should align with the interests of the individual and the needs of the institution.

- Provide honoraria or stipends for OERs that are produced.

- Contract the production of OERs to instructors.

Note that a number of costs associated with OER development and deployment, such as creating and adapting materials, implementing ICT infrastructures, creating a critical mass of those who have ICT skills, and providing workshops are typical activities any institution would execute in order to stay current.

\section{Producing Resources in Interoperable and Open Formats}

If OERs are to be produced inexpensively and shared, they should be produced with software that is freely available to everyone. In addition, OERs should be placed in linked repositories that can be accessed via a variety of digital devices. Currently, there are more than 2,080 repositories listed in the Directory of Open Access Repositories (see DOAR, http://www.opendoar.org/), of which 50 appear to be located in Africa. Perhaps OER Africa or the AVU OER Repository (see http://oer.avu.org/) could provide the portal to the various OER repositories in sub-Saharan Africa. As access to the Internet in sub-Saharan Africa is limited at this time, OERs must also be provided on CDs, DVDs, and/or paper so that they can be accessed offline.

Currently, OER developers in Africa tend to use the software with which they are familiar. This software is not likely to be open source; it may not be freely available to everyone because it is likely to be proprietary software, such as Microsoft (MS) Word. Text-based OER materials could be produced in rich text format (RTF), but MS Word is the most widely used software in the English-speaking world, and users in developed and developing countries are likely to have access to it (Wright, 2011a). Today, most word processors and common productivity tools, such as spreadsheet and presentation software, allow for conversion from one format to another. MS Word documents can easily be converted to OpenOffice Writer (see http://www.openoffice.org/product/writer.html), a free word processor that does not require institutions to pay a licensing fee. Some display features will 
not be the same as in MS Word, but the basic data can be viewed. If the OERs contain audio, video, and/or interactivity, it can be a little more difficult and sometimes almost impossible to convert seamlessly from one format to another. Hence, OER developers in Africa could meet to decide what standards they will follow and to review the standards periodically. For example, they could agree on using the free, open e-book standard ePub (set by the International Digital Publishing Forum) as ePub (see http://idpf.org/epub) can display content on most e-readers and smartphones.

Ideally, there should be interoperability among data, software, and services. "International and donor agencies should put extra effort toward the support of global platforms that enable the creation, translation, adaptation, and sharing of OER" (West, 2011, p. 40). The platforms should be able to cope with multiple technical formats that can be used by educators with basic word-processing skills (West, 2011). This concept has merit, but getting everyone in the global OER movement to agree on a standard may take considerable time, and the concept needs to take into account the fact that periodically, other technologies and software will need to be incorporated. Different standards emerge over time and are not always compatible-remember the VHS and Beta video standards? Whatever form these proposed global platforms may take, they must be maintained, updated, and financially supported by an organization or consortium. Currently, educators could use a number of repository management systems, such as DSpace (see http://www.dspace.org/). The free, open-source DSpace software is used by 1,283 academic institutions and organizations to store digital content, including texts, static images, videos, and data sets. The AVU OER Repository uses DSpace to store 219 modules covering biology, chemistry, education, ICT basic skills, mathematics, and physics in three languages (English, French, and Portuguese). This repository has been accessed by people from 180 countries.

Finding OERs can be a challenge because there is no agreed-upon standard for labelling them and because items are not consistently indexed in OER repositories. Various forms of metatagging have emerged, but there have been varying degrees of success with their application. However, all labelling should indicate the subject matter of the OER, identify for whom the resource was designed (e.g., primary, secondary, or university), provide a brief overview of the content, suggest how the materials could be used, and, where appropriate, list educational outcomes that the resource is attempting to facilitate. In addition, it should be noted whether items conform to government-dictated accessibility requirements and the principles of universal instructional design (UDI), which were developed to minimize or eliminate barriers in the teaching and learning process.

Since few OER repositories are linked, finding a suitable OER may take time as each repository, such as the University of Cape Town (UCT) OpenContent Directory (see http://opencontent.uct.ac.za/), may need to be searched individually. Yes, search tools such as Google do work, but a search engine that focuses on OERs would be beneficial. Search engines that work in a multilingual environment could locate a wider variety of OERs. Then, the content would need to be translated. Translation of world languages used to be difficult, but now some computer programs will do the translation with minimal obvious errors. Note, however, that successful translation depends on the recognition of cultural context and the 
translator's knowledge of the subject area relative to the community in which the information or skill will be applied. Currently, computer-based translators have no knowledge of the context or community in which the materials will be used. Therefore, prior to distributing a translated OER to students, educators should review the translation to ensure that the material will fit the local social and cultural contexts.

In order to ensure that learners can easily access OERs, educators in sub-Saharan Africa could decide on the software standards to be used in the region. This decision-making process could be conducted with the assistance of various OER-interested bodies, such as the African Development Bank, the Confederation of Open Access Repositories (see COAR, http://www.coar-repositories.org/), UNESCO, and the William and Flora Hewlett Foundation (a major force in advising on and supporting global OER efforts). The reality of the world of technology is that there will always be change; thus, standards must change over time. The best one can do is to agree to use open file formats wherever possible, along with the most commonly available software-until the next most commonly available software emerges.

\section{Establishing and Maintaining Quality}

How good can a free product be? This question has been raised among those who query the legitimacy and quality of OERs. Their perceptions about the quality of OERs have limited the uptake of these resources. But it is a valid question to ask: How can the quality of OERs be assured?

Quality is an elusive concept, as it can be defined differently by all who measure it and it is affected by the context in which the measurement is taken. The real measure of a quality course (or OER) is whether it helps learners achieve the stated learning outcomes. (Wright, 2011b, p. 1).

Education is one of the few human endeavours in which quality is decided by the creator rather than the user (McMartin, 2008). If an institution states that a resource is authoritative and/or provides the list of criteria used to define inputs into the design process, we tend to believe that the institution has produced a quality course. In almost any other human pursuit, quality is defined by the consumer or user of the product.

Two common approaches to the design of quality OERs are a centralized, carefully controlled, top-down approach and an open approach that invites contribution from everyone (Plotkin, 2010, p. 6). The development and review of OERs benefits from both approaches. The top-down approach leads to the establishment of criteria and guidelines that are consistently applied during the development and review process. The bottom-up approach is decentralized and more scalable and sustainable. OERs are subjected to mass peer reviewthe greater the number of eyes focused on the OER, the greater the amount of feedback that can be provided to improve the resource. Those OERs that are produced via a collaborative partnership of educational providers are likely to be more complete and suitable for a wide 
audience. If you knew that your work would be published online, wouldn't you present your best for the world to see? The fact that an OER can be seen by anyone often leads to more attention being paid to its quality.

At the AVU, modules for the Teacher Education Program were developed using a collaborative approach. Authors and reviewers from 12 universities in 10 participating countries were involved in the development and rigorous peer review of the teacher education modules. This collaborative process took into account the guidance of the Teacher Education Advisory Committee and the AVU Quality Assurance Framework (QAF). The latter was based on best practices obtained from international and African institutions. The implementation of the QAF has instilled confidence in the quality of the resources the institution produces and has fostered continuous improvement. Over time, it is expected that quality will be ingrained into the daily habits of university instructors and the fabric of the AVU community (African Virtual University, 2011d). The approach AVU uses for ensuring the quality of its modules could be adapted for the development and review of OERs used throughout subSaharan Africa. In addition, the criteria and success factors for quality distance-education materials and services developed by SAIDE (2004) could be revised and adapted for OERs. These criteria were developed with the assistance of educators from Botswana, Kenya, Namibia, and West Africa. Regardless of how the quality standards are crafted, they must be implemented and monitored.

Normally, when learning materials are designed, course developers know exactly who the learners will be and what their attributes are. They know what interests and motivates learners. They know how to make learning relevant to the learners' lives. However, when designing OERs, developers may not know who the actual users will be as anyone can access an OER. Consequently, OER developers must focus on designing learning resources that meet the needs of a specific audience and must clearly indicate who that audience is. Thus, the quality of the learning material can be judged by those for whom it was designed. Although feedback about the OER should be requested from all who use it, the feedback should be judiciously examined. As Wikipedia has discovered, not all feedback is helpful feedback that improves the accuracy, currency, and quality of its materials.

Due to the scarcity of resources and student support in sub-Saharan Africa, individual OERs may need to be more comprehensive than OERs produced for an audience who may have easy access to additional information. Developers in sub-Saharan Africa may need to provide a context for using the resource by including the following with each OER: introduction, learning objectives or outcomes, learning activities, self-assessment questions, answers to the questions, and sources of additional information. OERs should not be seen as a content dump, however; engagement should be built in.

OERs, like traditional resources, need to be updated. If no changes are made to an OER over time, the material may be become inaccurate or obsolete. Hence, efforts should be made to review and renew OERs at the same time that curriculum reviews are being conducted, perhaps once every $5-8$ years. Shorter review cycles are needed for subjects such as technology and health care, which change rapidly. 
Although this section has focused on the development and delivery of quality course content, attention also needs to be paid to the management of the educational institution and to the development and delivery processes. Institutions could consider the standards set by the International Organization for Standardization (see http://www.iso.org/iso/ iso 9000 essentials), which has established standards and guidelines that relate to a quality management system. Institutions may not want to become certified and receive the ISO 9001:2008 designation, but they could use the globally accepted ISO framework to improve their management functions and thereby create a more efficient and effective organization focused on learners.

\section{Providing Local Context}

Currently, most of the OERs that are available were developed in countries with strong economies. These resources may present points of view that are different from those that are customary and/or acceptable in Africa. The material may touch on cultural, social, political, and religious sensibilities. However, an educational experience should include exposure to new ideas and different ways of seeing the world. Thus, OERs from different parts of the world should be accessible in sub-Saharan Africa, although they may need to be modified to include additional explanations and examples with an African context. OERs should also be reviewed and modified to ensure that there is no explicit or implicit bias relative to age, culture or ethnicity, race, gender, or sexual preference. Biased opinions may be included as examples if they are directly related to the content of the course in which the OER may be used.

English is the mother language of only about 6\% of the global population (Vota, 2011), yet it seems to dominate the content on the Web. Children learn best when they are able to learn in their mother tongue or the language of their immediate environment. Adults, particularly adults who have little education, feel more comfortable using their mother tongue. If OERs are going to be accessible to a larger number of people, they must be available in a variety of languages, even though additional time and expense may be required to produce these materials. The challenge for each country in Africa is deciding the language that should be used in educational materials. Nigeria, for example, has 510 languages. However, its official language is English, even though English is not widely spoken in rural areas, where most of the country's 154,729,000 people live (UNICEF, 2010). In rural areas, the most commonly heard languages are Hausa, Igbo, and Yoruba. Producing OERs or translating OERs for use in multilanguage settings can take time and be expensive. Although the following quote was referring to challenges with literacy in multilingual settings, it also applies to languages used for OERs: "Decisions on language must balance political and ethnic sensitivity, pedagogical effectiveness, costs, and learner preferences” (UNESCO, 2006, p. 8). Each OER initiative needs to balance these factors. The TESSA Project, for example, has produced teaching materials in five languages, Arabic, English, French, isi-Xhosa, and Kiswahili, to meet the needs of its various audiences. TESSA is a consortium of 12 African universities, the United Kingdom Open University, and various international organizations such as the BBC World Service Trust and the Commonwealth of Learning. The consortium 
has produced OERs in teacher training that can be adapted for local needs in any country.

"How might the developed learn from the developing" (McMartin, 2008, p. 142)? Since most OERs are produced in countries with more advanced economies, it would be refreshing for people in Africa to develop OERs that see the world through their eyes, so others can obtain a better appreciation of the knowledge, skills, culture, and views of Africans. We need to hear the views of more southern voices in our global educational landscape.

\section{Informing the Public and Educating the Users}

OERs provide opportunities for individuals within and outside of a formal program of learning to improve themselves and gain information that they can use to help them make decisions about their lives. However, they must be aware of these opportunities and be able to find and evaluate them for relevancy to their situation. The public must be informed about OERs, their benefits, and their uses. In sub-Saharan Africa, those in formal educational programs may obtain this information from instructors who are not intimidated by technology or the perceived loss of their know-it-all status. Those in rural areas may not learn about OERs unless local teachers and community leaders are informed about these resources. Community leaders tend to focus on issues dealing with water, health, face-toface traditional instruction, and local politics. They are likely to think that technology is more suitable for those who live in urban settings and that technology doesn't address the basic needs of the local people. Yet there are OERs that can address the provision of clean drinking water, the improvement of face-to-face instruction, and health needs, such as the OERs available from the repository of the African Health OER Network (see www.oerafrica. org/healthoer). The public, as well as government and education leaders, must be sensitized to the flexible benefits of OERs.

Governments and institutions should consider launching a community inclusion initiative that involves key stakeholders and the public. They could launch a public relations or marketing plan that not only outlines the benefits or opportunities of OERs, but also addresses the myths, fears, and quality concerns as outlined earlier in this article. The plan should include training sessions that help users find and use OERs. Due to the large number of online resources, users must learn to conduct effective searches and to evaluate the items they find. Implementation of this public relations or marketing plan does not have to be expensive as students in formal educational programs could receive credit for finding OERs, constructing and evaluating them, and informing others how to use them. Youths everywhere seem to be able to master ICTs quicker than senior instructors who have not had technology as part of their educational tradition. By being involved in this public relations or marketing initiative, the learners would become more actively engaged in the learning process. They are likely to identify OERs that members of the community would find useful, create OERs that instructors can improve upon and use with future students, and find sources for OERs beyond the familiar sources, such as Academic Earth (see http://academicearth. org/), College Open Textbooks (see http://collegeopentextbooks.org/), the Community College Consortium for Educational Resources (see CCCOER, http://oerconsortium.org/), Connexions (see http://cnx.org/), Curriki for K-12 (see http://www.curriki.org/), MER- 
LOT (see http://www.merlot.org/), MIT OpenCourseWare (see http://ocw.mit.edu/index. htm), OER Africa, OER Commons (see http://www.oercommons.org/), Open Courseware Consortium (see http://www.ocwconsortium.org/), Open Course Library (see http://www. opencourselibrary.org/), OpenLearn, Project Gutenberg (see http://www.gutenberg.org/), TESSA, VUSSC, and WikiEducator. Many free resources that could be used for educational purposes lie outside of formal OER repositories. If additional financial resources were available, teachers and community-based health workers could be contracted to inform the public about OERs, demonstrate their uses, and show how OERs can be accessed.

\section{Taking the Initiative: Making a Commitment}

Implementing OERs and technology is not a panacea for all that ails the various educational systems in Africa. As this article has shown, there are many challenges to be overcome. But the article also presented possible solutions to address these challenges. The solutions are not limited to those presented here as additional experience and future research may lead to novel yet heretofore-unseen pathways.

\section{Creating and sustaining a vision for OERs.}

The vision does not have to be based on OERs and technology in particular; it could be based on how one could best improve the provision of safe drinking water and sanitary conditions, the prevention of diseases, or the increased production of foodstuffs. Alternatively, the vision could be more focused and centre on how to improve the quality of education for minimal financial costs. Although we often think of administrators as drivers of educational visions, it may be the youth who become drivers of change as they are desperate to get ahead and are willing to try something new. The youth may put pressure on educators and administrators to act. In North America, for example, youth have encouraged traditional faculty to use more technology in the classroom.

\section{Developing and distributing resources with an open license.}

As the creation and distribution of materials with an open license sweeps through the publishing industry in other parts of the world, it is likely to sweep through Africa. Unless educators in Africa start to produce materials with an open license and contribute to the global movement, they may feel left behind and become inundated with materials that do not address their unique social and cultural norms and interests. By developing and distributing their own OERs, they can counter the influences of others. Thus, it is imperative that they find OER development and deployment mechanisms that work best for them. But no one has to wait for grand visions or policies to be formulated or enacted in order to become part of the OER movement. All one needs to do is to share educational materials he or she has produced under an open copyright license. With the use of ICTs, digitized material can be easily shared locally and internationally.

\section{Improving the technology infrastructure.}

During the last 10 years, there have been significant changes in the technology infrastruc- 
ture in Africa; this will continue. Many African countries have partnered with China to build roads that are used by everyone to transport themselves and their goods. The roads are transforming people's lives. Similar partnerships could be established with other nations to develop the technology and electrical infrastructure that could increase efficient communication and thus advance the transmission of ideas via computers and the ubiquitous mobile phones. However, until researchers develop a smartphone that can project a larger image, it will be difficult to use these phones effectively for teaching subjects such as the sciences, which require detailed visual displays. Furthermore, the input devices need to accommodate the size of a human hand so that information can be entered quickly, or voice-recognition systems must be designed to permit effortless use and accurate translation of African languages.

\section{Establishing communities of educational collaborators.}

The British Open University is widely known for establishing and promoting course development in a collaborative manner. Collaboration, especially from a survival point of view, has been the basis of many cultures in Africa. If African educators want their societies to grow and thrive, how can they build upon their collaborative history and apply their principles of sharing to education? Diallo, Wangeci, and Wright (2012) suggested one collaborative model, but what other models could be developed that align with traditional collaboration in Africa?

\section{Sustaining involvement.}

Any new initiative brings excitement and an inflow of foreign funds. However, excitement and funds wane as challenges are encountered and foreign donors lose interest. What is the vision or driving force that will sustain interest in Africa for OERs when challenges are encountered and external funds are reduced? If OERs can be directly linked to improvements in health, education, and economic outlook for the people, then it is more likely that governments will be willing to provide funding to sustain OER efforts. OER initiatives may not need as much new funding as governments may first believe. Existing funds used to develop traditional materials could be used to develop OERs instead, and when these resources are exchanged with other people who provide similar but different materials, everyone benefits. In order to bolster this argument, some current facts about education material acquisition and development costs in Africa would be helpful.

\section{Producing resources in interoperable and open formats.}

There is a plethora of software tools that can be used to create and distribute OERs. Some are highly promoted by external funders who want to grow their industry back home. If the OERs are to be produced and used in Africa, shouldn't the simplest and most accessible software be used rather than the more eloquent and/or Internet-intensive solution? Would it be practical to suggest that all OERs be developed using open-source software? Would it be beneficial for African educators to conduct a survey of what they currently use and de- 
cide on one set of standards for materials developed for laptop computers and a separate set of standards for mobile handheld devices? Selecting standards for static material such as text, photographs, and streaming video should be relatively easy; choosing standards that can be used for interactive material will be more difficult. Also, it must be recognized that as technology advances, standards will need to be modified.

\section{Establishing and maintaining quality.}

African educators and government officials are rightly concerned about the quality of OERs, and this issue has prevented a number of them from embracing OERs. Yet they do not appear to be as concerned with the quality of material used in traditional instruction. From our experience working on several educational projects in Africa, quality is a concern throughout the educational system, particularly the use of outdated material, the predominance of low-level cognitive objectives, the emphasis on the memorization of content rather than the active engagement of learners in the application of knowledge, and the use of material that presents sociological, cultural, and economic views that have not been explained or adapted for use by local learners. As noted by Jung and Latchem (2012) in reference to ODL, quality assurance can be a contentious issue. Quality in education is usually defined by the inputs, but perhaps the outputs of the education system would yield a better measure of quality. If OERs enable an individual to do something that he or she could not do before, shouldn't they be defined as quality OERs?

\section{Providing local context.}

One of the goals of education is to introduce new ideas. But if the ideas are to have meaningful impact, they must be adapted for local use. What effective and efficient adaptation mechanisms could be established in Africa? Can Africa truly afford to adapt materials to its many languages? Or is it sufficient to produce materials in just a few languages and have local teachers verbally adapt the materials? Whatever materials are produced, it would be beneficial for learners and instructors if the materials produced in Africa were placed in searchable repositories that are linked to a common portal.

\section{Informing the public and educating the users.}

Unless OERs are embraced by teachers, community health professionals, and community leaders, it is unlikely that the use of such resources will be sustained. Perhaps African educators and government leaders could learn from Brazil, India, Peru, and Uruguay some of the many lessons learned in trying to implement educational technology, including OERs. These lessons are discussed in the World Bank's ongoing EduTech Debate (see https:// edutechdebate.org/) and EduTech Blog (see http://blogs.worldbank.org/edutech/), which provide a cornucopia of ideas that could be investigated for their applicability to countries and regions with weak economies, such as Africa. Then African leaders will need to reflect on educational development projects in Africa and decide what is best for them-what models of OER implementation are best for sub-Saharan Africa? 
It is inevitable that the development and deployment of OERs will continue to expand in sub-Saharan Africa as they can benefit independent learners as well as those registered in distance and traditional institutions. Although OERs can be used informally and formally by themselves, the use of a single OER from organizations such as AVU, TESSA, and OER Africa does not an education make. Quality OERs are only one component of an effective course or program offered by educational institutions. For many learners, access to content is not enough (Lane, 2008; McMartin, 2008), even if the resources are accessed from the award-winning AVU OER Repository. To maximize the full potential of OERs, they should be incorporated into a system of effective learner support, active engagement, quality interaction with instructors and fellow learners, critical and timely feedback, credible assessment, excellence in research, and recognized accreditation-qualities that also apply to traditional education. In addition, institutions may need to develop or adapt internal policies that facilitate the use of OERs, and governments may need to permit public institutions to use OERs that have not been created by a specific government agency.

Despite the emergence of "Do-It-Yourself Universities" (Kamenetz, 2010) and the OER University, there will always be a need for formal institutions such as AVU, SAIDE (a founding member of the OERu), UCT, and UoM. Using the experiences of these organizations, as well as the knowledge and skills of the African Development Bank, COL, UNESCO, and the William and Flora Hewlett Foundation, it will be possible to advance the implementation of OERs in sub-Saharan Africa. OER Africa, the AVU OER Repository, and TESSA are just a few successful projects in sub-Saharan Africa. African leaders should take the initiative to build on the experiences of the aforementioned organizations in order to ensure that the potential of OERs is attained as the employment of OERs may have a significant impact on the accessibility and quality of education-a driver of social and economic growth. OER development and deployment is one of several pathways that will contribute to achieving education for all.

\section{Acknowledgements}

Bakary Diallo, rector, African Virtual University, Kenya, for encouraging us to write about the transformative potential of OER development and deployment in sub-Saharan Africa, Genevieve Gallant, president, GG Consultants Ltd., Canada, for reviewing the manuscript, and Bethel Masauli, former head, Malawi College of Distance Education, Malawi, for her firm belief that constructive will and the collaborative efforts of learners, educators, and decision makers will lead to significant improvements in Africa. 


\section{References}

African Virtual University. (2011a). Open, Distance, and eLearning (ODeL) Centres. Nairobi: African Virtual University. Retrieved from http://www.avu.org/AVU-Multinational-Support-Project/odel-centers.html

African Virtual University. (2011b). AVU Capacity Enhancement Program-ACEP. Nairobi: African Virtual University. Retrieved from http://www.avu.org/AVU-Multinational-Support-Project/avu-capacity-enhancement-program-acep.html

African Virtual University. (2011c). Teacher Education Virtual Consortium. Nairobi: African Virtual University. Retrieved from http://www.avu.org/Teacher-EducationVirtual-Consortium/teacher-education-virtual-consortium.html

African Virtual University. (2011d). The design and development of a quality assurance framework. Nairobi: African Virtual University. Retrieved from http://www.avu. org/Teacher-Education-Programme/design-development-quality-assuranceframework.html

Ali, L. (2011, October 12). The digital revolution in sub-Saharan Africa. Aljazeera.net. Retrieved from http://english.aljazeera.net/indepth/featur es/2011/10/201110108635691462.html

Allen, N. H. (2010, September 1-3). Education for all: Access? Equity? Quality? Presentation for the Standing Conference of Presidents (SCOP) Policy Forum held at Pretoria, South Africa. Presentation slides available at http://www.unisa.ac.za/ scop2010/docs/education-for-all_scop2010.pdf

Anderson, T. (2009, June 7). Are we ready for open educational resources? Presentation at the $23^{\text {rd }}$ ICDE World Conference, Maastricht, The Netherlands.

Atkins, D. E., Brown, J. S., \& Hammond, A. L. (2007, February). A review of the open educational resources (OER) movement: Achievements, challenges, and new opportunities (Report to the William and Flora Hewlett Foundation). Retrieved from http://www.hewlett.org/uploads/files/ReviewoftheOERMovement.pdf

Bates, A. W., \& Sangrà, A. (2011). Managing technology in higher education: Strategies for transforming teaching and learning. San Francisco: Jossey-Bass Wiley.

Bloom, D., Canning, D., \& Chan, K. (2006, February). Higher education and economic development in Africa. Washington, DC: Human Development Sector, Africa Region, The World Bank. Retrieved from http://www.arp.harvard.edu/AfricaHigherEducation/Reports/BloomAndCanning.pdf

Butcher, N. (2011). A basic guide to open educational resources (OER). Vancouver: The Commonwealth of Learning. Retrieved from http://www.col.org/PublicationDoc- 
uments/Basic-Guide-To-OER.pdf

Calandro, E. (2011). 2011 Fair mobile: Dynamic changes. Cape Town, South Africa: Research ICT Africa. Retrieved from http://www.researchictafrica.net/docs/Fair Mobile Prices\%20Q2-v04.pdf

Craddock, A. (2011, October 2). No quick remedy for Africa's Internet gap. IDN-InDepthNews. Retrieved from http://www.indepthnews.info/index.php/globalissues/446-no-quick-remedy-for\%20africas-internet-gap

Daniel, J. (2010, October 14). The Commonwealth of Learning: How a small agency achieves development impact. Presentation for the Canadian International Development Agency, Ottawa, Canada. Retrieved from http://www.col.org/SiteCollectionDocuments/Daniel 101014CIDABrownBag.pdf

Daniel, J. (2011, September 11). GLOBAL: New guidelines for open educational resources. University World News. Retrieved from http://www.universityworldnews.com/ article.php?story=20110909190605514

D’Antoni, S. (2009, February). Open educational resources: Reviewing initiatives and issues. Open Learning, 24(1), 3-10.

Diagne, A. (2006, November 22-24). Investing in people: Education and health. African Development Bank Seminar, Tunis, Tunisia. Retrieved from http://www.afdb.org/ fileadmin/uploads/afdb/Documents/Knowledge/o9484263-EN-INVESTIRSURLESGENS-PR-DIAGNE-.PDF

Diallo, B., Wangeci, C., \& Wright, C. R. (2012). Approaches to the production and use of OERs: The African Virtual University experience. In R. McGreal, W. Kinuthia, \& S. Marshall (Eds), Open educational resources (working title), Athabasca, Canada: University of Athabasca Press. Free online version of the book chapter will be available at http://www.aupress.ca/

Downes, S. (2007). Models for sustainable open educational resources. Interdisciplinary Journal of Knowledge and Leaning Objects, 3. Retrieved from: http://ijklo.org/ Volume3/IJKLOv3p029-044Downes.pdf

Gross, D. A. (2006, February 7). New technologies and the rise of political liberty. Remarks made at the 2006 Grafstein Lecture in Communications, Faculty of Law, University of Toronto, Canada. Retrieved from http://www.law.utoronto.ca/faculty content.asp?itemPath=1/14/3/o/o\&contentId=1407

Hesselmark, O. (2010). Internet prices in Africa: A comparative study. Retrieved from http://www.schoolnetafrica.org/fileadmin/resources/Internet prices in Africa. pdf 
Hilton, J., III, Wiley, D., Stein, J., \& Johnson, A. (2009). The four R's of openness and ALMS analysis: Frameworks for open educational resources. Retrieved from https:// www.redhat.com/archives/osdc-edu-authors/2011-January/pdfoziqzY4Mtn.pdf

International Institute for Communication and Development. (2011, October 24). Recommendations to the Dutch Platform RIO 2O+: ICT for a greener economy. The Hague, The Netherlands: International Institute for Communication and Development. Retrieved from http://zunia.org/uploads/media/knowledge/IICD\%20Recommendations\%20Rioplus201323929929.pdf

Internet World Stats. (2011, March 31). World Internet usage and population statistics. Bogota, Colombia: Miniwatts Marketing Group. Retrieved from http://www.internetworldstats.com/stats.htm

Jung, I. \& Latchem, I. (Eds.) (2012). Quality assurance and accreditation in distance education and e-learning: Models, policies and research. New York, NY: Routledge.

Kamenetz, A. (2010). DIY U: Edupunks, edupreneurs and the coming transformation of higher education. White River Junction, VT: Chelsea Green Publishing.

Kavuma, R. M. (2011, September 9). In Africa's universities, quantity threatens quality. UK Guardian. Retrieved from http://www.guardian.co.uk/global-development/ poverty-matters/2011/sep/o9/africa-university-funding-crisis

Kiptalam, G. K., \& Rodrigues, A. J. (2010, June). Internet utilization: A case of connected rural and urban secondary schools in Kenya. International Journal of Computing and ICT Research, 4(1), 49-63. Retrieved from http://ijcir.org/volume4-number1/article6.pdf

Kasumuni, L. (2011, April 18). Delivering video by mobile phone to classrooms in Tanzania. eLearning Africa Newsportal. Retrieved from http://www.elearning-africa.com/ eLA Newsportal/delivering-video-by-mobile-phone-to-classrooms-in-tanzania/

Lake, A. (2010, September 17). For children, education is almost everything. This is Africa: A global perspective. http://web.thisisafricaonline.com/news/2010/09/17/ anthony-lake-for-children-education-is-almost-everything/

Lambert, S. (2004, April 23). Teachers' pay and conditions: An assessment of recent trends in Africa. Paris: UNESCO. Retrieved from http://unesdoc.unesco.org/ images/0014/001466/146656e.pdf

Lane, A. (2008). Widening participation in education through open educational resources. In T. Iiyoshi \& M. S. V. Kumar (Eds.), Opening up education: The collective advancement of education through open technology, open content, and open knowledge (pp. 149-163). Cambridge, MA: MIT Press. Retrieved from http://mitpress. mit.edu/books/chapters/0262033712chap10.pdf 
Lerman, S. R. Miyagawa, S., \& Margulies, A. H. (2008). OpenCourseWare: Building a culture of sharing. In T. Iiyoshi \& M. S. V. Kumar (Eds.), Opening up education: The collective advancement of education through open technology, open content, and open knowledge (pp. 213-227). Cambridge, MA: MIT Press. Retrieved from http://mitpress.mit.edu/books/chapters/o262033712chap14.pdf

McAndrew, P. (2010). Fostering open educational practices. ICT in teacher education: Policy, open educational resources, and partnerships. Proceedings of International Conference IITE-201O, November 15-16, 2010, St. Petersburg, Russia. Paris: UNESCO Institute for Information and Technologies in Education, pp. 124-129. Retrieved from http://unesdoc.unesco.org/images/o019/001936/193658e.pdf

McMartin, F. (2008). Open educational content: Transforming access to education. In T. Iiyoshi \& M. S. V. Kumar (Eds.), Opening up education: The collective advancement of education through open technology, open content, and open knowledge (pp. 135-147). Cambridge, MA: MIT Press. Retrieved from http://mitpress.mit. edu/books/chapters/0262033712chapg.pdf

Mungai, M. (2011). 12 challenges facing computer education in Kenyan schools. Retrieved from http://www.ictworks.org/news/2011/09/12/12-challenges-facing-computer-education-kenyan-schools?

Ngare, P. (2007, June 8). Kenya: Country takes steps to adopt e-learning. allAfrica.com. Retrieved from http://allafrica.com/stories/200706080176.html

Plotkin, H. (2010). Free to learn: An open educational resources policy development guidebook for community college governance officials. San Francisco: Creative Commons. Retrieved from http://wiki.creativecommons.org/images/6/67/FreetoLearnGuide.pdf

Polgreen, L. (2012, January 10). Fatal stampede in South Africa points up university crisis. The New York Times. Retrieved from http://www.nytimes.com/2012/01/11/ world/africa/stampede-highlights-crisis-at-south-african-universities.html?hp

Provost, C. (2011, April 27). Education in Africa: Where does the money go? UK Guardian. Retrieved from http://www.guardian.co.uk/news/datablog/2011/apr/27/africaeducation-spending-aid-data

Prozonic, C. (2011, December 31). A Fulbright student seeks a greater voice. Lehigh University News. Retrieved from http://www4.lehigh.edu/news/newsarticle. aspx?Channel=/Channels/News: $+2011 \&$ WorkflowItemID $=3$ bd2592b-57bc-47c99952-73617e95693e

Ribeiro, J. (2011, October 5). India's low-cost tablet is made by Canada's DataWind. PC World. Retrieved from http://www.pcworld.com/businesscenter/article/241156/ 
indias lowcost tablet is made by canadas datawind.html

SAIDE. (2004). Distance education and open learning in sub-Saharan Africa: Criteria and conditions for quality and critical success factor. Johannesburg and Vancouver: South African Institute for Distance Education and the Commonwealth of Learning. Retrieved from http://www.col.org/SiteCollectionDocuments/o4DEinS $\underline{\text { SA CriteriaforQuality.pdf }}$

Sunday, F. (2012, January 4). E-learning project for primary and second education on course. Business Daily Africa. Retrieved from http://www.businessdailyafrica.

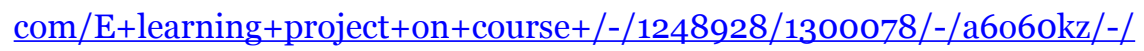

Thornton, L. (2008, September 25). Why African governments need to listen to the case for "open access" to international communications infrastructure. Association for Progressive Communications News. Retrieved from http://www.apc.org/en/ node $/ 6878$

Trucano, M. (2007, October 16-19). What do we know about the effective uses of information and communication technologies in education in developing countries? Paper presented at the OECD International Expert Seminar on New Millennium Learners, Cheju Island, Korea.

Trucano, M. (2011, December 9). The Aakash, India’s \$35(?) tablet for education. EduTech Blog. Washington, DC: The World Bank. Retrieved from http://blogs.worldbank. org/edutech/aakash

UN Economic Commission for Africa. (2007, November 6). Connect Africa summit adopts five goals to bridge the digital divide in Africa. Retrieved from http://www.uneca. org/eca resources/news/2007/071106ConnectAfrica.htm

UNESCO. (2006). Education for All global monitoring report 2006: Executive summary. Retrieved from http://www.unesco.org/education/GMR2006/full/execummary. pdf

UNESCO. (2011). Global education digest: Comparing education statistics across the world. Montreal, Canada: Institute for Statistics of the United Nations Educational, Scientific, and Cultural Organization. Retrieved from http://www.uis.unesco. org/Library/Documents/global education digest 2011 en.pdf

UNESCO-COL. (2011). UNESCO/COL guidelines for open educational resources (OER) in higher education: Draft, United Nations Educational, Scientific, and Cultural Organization and Commonwealth of Learning: Paris and Vancouver. Retrieved from http://oerworkshop.weebly.com/uploads/4/1/3/4/4134458/2011.04.22. oer guidelines for higher education.v2.pdf

UNICEF. (2010, March 2). At a glance: Nigeria. Retrieved from http://www.unicef.org/ 
infobycountry/nigeria statistics.html

United Nations. (1948). Universal Declaration of Human Rights. New York: The United Nations. Retrieved from http://www.un.org/en/documents/udhr/

United Nations. (2009). The Millennium Development Goals report 2009. New York: The United Nations. Retrieved from http://www.un.org/millenniumgoals/pdf/MDG Report 2009 ENG.pdf

United Nations. (2011). The Millennium Development Goals report 2011. New York: The United Nations. Retrieved from http://www.un.org/millenniumgoals/11 MDG\%20Report EN.pdf

Vota, W. (2011, September 12). Creating indigenous language content with universal design in early literacy. Educational Technology Debate. Retrieved from https:// edutechdebate.org/open-discussion/creating-indigenous-language-content-withuniversal-design-in-early-literacy/

Walker, E. (2005). A reality check for open education. Utah: Open Education Conference. Retrieved http://www.archive.org/details/OpenEd2005ARealityCheckforOpenEducation

Wiley, D. (2009, November 16). Defining open. Open Content Blog. Retrieved from http:// opencontent.org/blog/archives/1123

West, P. G. (2011). Background and action paper on OER. Menlo Park, California: The William and Flora Hewlett Foundation. Retrieved from http://www.paulwest.org/ public/Background and action paper on OER.pdf

Wolfenden, F. (2008). The TESSA OER experience: Building sustainable models of production and user implementation. Journal of Interactive Media in Education, 3. Retrieved from http://oro.open.ac.uk/20664/1/F. Wolfenden TESSA OER.pdf

World Bank. (2006). Information and communication for development, global trends, and policies. Washington, DC: The World Bank. Retrieved from http://www-wds. worldbank.org/external/default/WDSContentServer/WDSP/IB/2006/04/20/00 0012009 20060420105118/Rendered/PDF/359240PAPERoIn101OFFICIALOU SEoONLY1.pdf

World Bank. (2010). Directions in development: Human development-Financing higher education in Africa. Washington, DC: The World Bank. Retrieved from http:// siteresources.worldbank.org/EDUCATION/Resources/278200-1099079877269/ Financing higher edu Africa.pdf

Wright, C. R. (2010, August 5). Do we have to wait for everyone to have a bicycle before anyone can have a car? EduTech Blog. Washington, DC: The World Bank. Retrieved 
from http://blogs.worldbank.org/edutech/comment/reply/583/986

Wright, C. R. (2011a, August 18). Why distribute documents in MS Word or OpenOffice for an international audience? The Association of Learning Technology Online Newsletter. Retrieved from http://newsletter.alt.ac.uk/2011/o8/why-distributedocuments-in-ms-word-or-openoffice-for-an-international-audience/

Wright, C. R. (2011b) Developing and reviewing online courses: Items for consideration. The Association of Learning Technology Online Newsletter. Retrieved from http://newsletter.alt.ac.uk/2011/11/developing-and-reviewing-online-coursesitems-for-consideration/

\section{Athabasca University $\mathbf{1}$}

(ㅇ) (1) 